\title{
Docosahexaenoic Acid \& Visual Functioning in Preterm Infants: a Review
}

$$
\text { Carly Molloy }{ }^{1,2} \text { Lex W Doyle }{ }^{1,2,3} \text { Maria Makrides }{ }^{4,5,6} \text { Peter J Anderson }{ }^{1,3}
$$

1. Murdoch Childrens Research Institute, Melbourne, Australia

2. Royal Women's Hospital, Melbourne, Australia.

3. University of Melbourne, Australia.

4. Women's and Children's Health Research Institute, North Adelaide, Australia

5. Women's and Children's Hospital, North Adelaide, Australia

6. School of Paediatrics and Reproductive Health, University of Adelaide

Correspondence to Carly Molloy, PhD

Critical Care and Neurosciences

Murdoch Childrens Research Institute

Royal Children's Hospital

Flemington Road

Parkville, VIC 3052

Australia.

Ph: +61399366786

Email: carly.molloy@mcri.edu.au

Running head: Docosahexaenoic Acid \& Visual Functioning in Preterm Infants: a Review.

Word count: Abstract $=276 ;$ Manuscript $=6,377$ 


\title{
Docosahexaenoic Acid \& Visual Functioning in Preterm Infants: a Review
}

\author{
Abstract \\ Preterm children are at risk for a number of visual impairments which can be important for a range \\ of other more complex visuocognitive tasks reliant on visual information. Despite the relatively high \\ incidence of visual impairments in this group there are no good predictors that would allow early \\ identification of those at risk for adverse outcomes. Several lines of evidence suggest that \\ docosahexaenoic acid (DHA) supplementation for preterm infants may improve outcomes in this \\ area. For example, diets deficient in the long-chain polyunsaturated fatty acid DHA have been \\ shown to reduce its concentration in the cerebral cortex and retina, which interferes with \\ physiological processes important for cognition and visual functioning. Further, various studies with \\ pregnant and lactating women, as well as formula-fed infants, have demonstrated a general trend \\ that supplementation with dietary DHA is associated with better childhood outcomes on tests of \\ visual and cognitive development over the first year of life. However, research to date has several \\ methodological limitations, including concentrations of DHA supplementation that have been too \\ low to emulate the in utero accretion of DHA, using single measures of visual acuity to make \\ generalised assumptions about the entire visual system, and little attempt to match what we know \\ about inadequate DHA and structural ramifications with how specific functions may be affected. \\ The objective of this review is to consider the role of DHA in the context of visual processing with a \\ specific emphasis on preterm infants and to illustrate how future research may benefit from \\ marrying what we know about structural consequences to inadequate DHA with functional \\ outcomes that likely have far-reaching ramifications. Factors worth considering for clinical \\ neuropsychological evaluation are also discussed.
}

Keywords: docosahexaenoic acid (DHA), visual processing, preterm infants, retina, dorsal stream 


\section{Introduction}

Docosahexaenoic acid (DHA, 22:6n-3), an (omega-3) n-3 long chain polyunsaturated fatty acid, is found in high concentrations in both the cerebral cortex and the retina and is important for a number of physiological processes. The neural networks involved in visual processing are extensive and early disruption to this integrated system may have detrimental consequences for the processes important for vision, which may in turn compromise other functional skills. Animal studies have illustrated that diets deficient in n-3 fatty acids, including $\alpha$-linolenic acid and DHA, have negative consequences for visual and behavioural functioning, leading to speculation that supplementation with n-3 fatty acids in human infants might improve functioning in a range of visual and cognitive domains.

During the last trimester of pregnancy a substantial amount of DHA is transferred from mother to fetus; thus infants born early (e.g. very preterm infants; $<32$ weeks' gestational age) are denied adequate intrauterine supply of DHA at a stage when brain growth is at its greatest. Consistent with the premise that visual processes are reliant on adequate DHA concentrations early in development, very preterm children exhibit higher than expected rates of refractive errors, strabismus, amblyopia, and deficient visual perceptual skills (Cioni et al., 2000; Downie, Jakobson, Frisk, \& Ushycky, 2003; Fielder, 1998; A. R. O'Connor et al., 2002; A. R. O'Connor et al., 2004; Powls, Botting, Cooke, Stephenson, \& Marlow, 1997; Stephenson et al., 2007). To understand how DHA affects visual processing, very preterm infants may serve as a useful model. The objectives of this review are to i) consider the role of DHA and how it relates to visual processing beyond what is already known about visual acuity, ii) discuss why preterm infants may be more susceptible for visual impairments due to inadequate DHA, iii) examine evidence for the effects of DHA supplementation in preterm infants, and iv) highlight areas that warrant further research.

\section{Prematurity}

Preterm birth, defined as a birth of less than 37 completed gestational weeks (WHO, 1970), is a major public health concern. It is associated with more than two-thirds of all perinatal deaths (Lumley, 2003) and approximately 75\% of neonatal morbidity, e.g. neurocognitive, pulmonary, and ophthalmological problems (Wen, Smith, Yang, \& Walker, 2004). Children born preterm are at increased risk for a range of neurodevelopmental difficulties compared with their full term peers, such as attention difficulties, memory and learning problems, academic underachievement, and 
visual motor integration deficits (e.g. (P. J. Anderson \& Doyle, 2003; Aylward, 2005; Bhutta, Cleves, Casey, Cradock, \& Anand, 2002; Hack et al., 2005)). Visual processing is an area of particular concern, with deficits reported in visual acuity (Evensen et al., 2009; Stephenson, et al., 2007), contrast sensitivity (Cooke, Foulder-Hughes, Newsham, \& Clarke, 2004; Powls, et al., 1997), stereopsis (Cooke, et al., 2004; Stephenson, et al., 2007), motion processing (Jakobson, Frisk, \& Downie, 2006; MacKay et al., 2005; Pavlova, Sokolov, Birbaumer, \& Krageloh-Mann, 2006; N. M. Taylor, Jakobson, Maurer, \& Lewis, 2009), and spatial perception (Pavlova, Sokolov, \& KragelohMann, 2007), all skills that are important for more complex and adaptive visual tasks such as classroom learning, and overall school performance (Cooke, et al., 2004; Grisham, Powers, \& Riles, 2007; Maples, 2003; Powls, et al., 1997), as well as social interaction and cognition (Aylward, 2002; J. P. Mitchell, 2006; Pelphrey \& Carter, 2008).

Preterm birth per se, early visual experiences, and various perinatal factors, such as retinopathy of prematurity (ROP), brain injury, and oxygen therapy during the neonatal period potentially contribute to adverse visual processing outcomes in this population. Despite the reported associations between certain perinatal variables and visual difficulties (Buksh, Dai, \& Kuschel, 2008; Cioni, et al., 2000; Eken, de Vries, van der Graaf, Meiners, \& van Nieuwenhuizen, 1995; Kushner, 1982; Nissenkorn, Yassur, Mashkowski, Sherf, \& Ben-Sira, 1983; Quinn et al., 1998; Ricci et al., 2011) it remains difficult to identify those preterm children at greatest risk for visual impairments. Different perinatal risk variables may differentially affect the developing visual system resulting in differing profiles of visual impairment. This is important because understanding the mechanisms for visual impairment in this population has ramifications for perinatal care, such as identifying optimal oxygen levels and specific nutrients and agents that might optimise ocular and cortical development.

\section{Docosahexaenoic acid (DHA)}

Docosahexaenoic acid (DHA), in which very preterm infants are deficient, may be one perinatal factor associated with the high prevalence of visual deficits in this population. The relationship between preterm birth and DHA is an area that has not been sufficiently evaluated but may serve as a useful model to understand both the importance of DHA in neonatal visual development, as well as provide a better understanding of the etiology of visual deficits exhibited by preterm infants. In particular, research has shown that DHA differentially affects parts of the visual system, such as rod photoreceptors and $\mathrm{M}$ retinal ganglion cells, and yet visual functions that are most likely to be implicated by damage to these structures have not been assessed, either in the short- or long-term. 
Humans have a limited ability to synthesise DHA from precursor $n-3$ fatty acids and thus it is mostly acquired through dietary sources such as fish, meat, seed oils, and eggs (Decsi \& Koletzko, 1994). The DHA status of a developing fetus depends on that of its mother, confirmed by data indicating a positive relationship between maternal DHA consumption and fetal DHA status, as reflected by increased concentrations of DHA in erythrocyte cell membranes, umbilical blood, and infant plasma (Birch, Hoffman, Uauy, Birch, \& Prestidge, 1998; Connor, Lowensohn, \& Hatcher, 1996; Le, Meisel, de Meijer, Gura, \& Puder, 2009; Smuts, Borod, Peeples, \& Carlson, 2003; van Houwelingen et al., 1995; Velzing-Aarts et al., 2001). DHA is a crucial component for synthesis of brain tissue, metabolism of neurotransmitters, cellular differentiation, and synaptogenesis (Sabel, LundqvistPersson, Bona, Petzold, \& Strandvik, 2009). The placenta actively transports DHA into the fetal circulation during gestation (Crawford et al., 1997; Hornstra, Al, van Houwelingen, \& Foreman-van Drongelen, 1995) and the rate of transfer increases substantially during the last trimester; in fact $80 \%$ of the brain DHA accrues in the fetus from 26 weeks' gestational age until term (Sabel, et al., 2009). This coincides with the time where the velocity of brain growth is at its greatest (Huppi et al., 1998; Makrides, Neumann, Byard, Simmer, \& Gibson, 1994; Smithers, Gibson, McPhee, \& Makrides, 2008). Preterm infants are considered insufficient in DHA due to the loss of intrauterine supply during the last months of pregnancy.

\section{DHA and the visual system}

The highest levels of DHA in the body are found in the retina and cerebral cortex (Neuringer, Connor, Lin, Barstad, \& Luck, 1986). Depletion of DHA from the retina and the cortex is speculated to alter their physical and functional properties (Neuringer, et al., 1986), which may affect functions important for accurate visual processing.

DHA is needed for photo-transduction, the process of transforming light into an electrophysiological signal (Litman \& Mitchell, 1996; Niu, Mitchell, \& Litman, 2001) and for the regeneration of rhodopsin, the light sensitive pigment in the retina; the absorption of light by rhodopsin is the first step in vision (Aveldano, 1988; Bush, Malnoe, Reme, \& Williams, 1994; Chen, Houghton, Brenna, \& Noy, 1996). DHA accounts for $50 \%$ of the total fatty acids in the structural phospholipids of the outer segment disk membranes of the photoreceptor (R. E. Anderson \& Risk, 1974), which creates a high degree of membrane fluidity (Neuringer, Anderson, \& Connor, 1988). Experiments conducted by Rotstein, Politi, and Aveldano (1998) provide evidence that the availability of phospholipids enriched in DHA, required for building photoreceptor outer segments, at the correct developmental period is one factor that is critical for the survival and differentiation of photoreceptor cells. DHA is 
also important for brain myelination through its protection of premyelinating oligodendrocytes, which ensheath developing axons and are the precursors to myelin-forming oligodendrocytes (Volpe, 2009), and stimulation of oligodendroglial cell differentiation (Brand et al., 2010; van Meeteren, Baron, Beermann, Dijkstra, \& van Tol, 2006). Furthermore, Norcia et al. (1990) proposed that changes in the efficiency of photoreceptors might influence neuronal factors such as myelination of the optic nerve, or changes in synaptic efficiency, ultimately affecting the development of some visual functions. Consistent with this view, visual evoked potential (VEP) studies have demonstrated that preterm infants fed formulas without DHA have VEP wave latencies that are significantly longer in comparison with those with some DHA, suggesting slower maturation of optic pathways and the visual cortex (Birch, Birch, Hoffman, \& Uauy, 1992; Faldella et al., 1996; D. L. O'Connor et al., 2001).

The development of the human retina requires a complex interaction of neural and vascular tissues which begins in early gestation and continues into mid-childhood. The processes involved in retinal maturation include generation of rods and cones and reorganisation and migration of photoreceptors (Hendrickson \& Drucker, 1992; Hollenberg \& Spira, 1973; Narayanan \& Wadhwa, 1998). During fetal development all cell types in the retina appear in a central-to-peripheral gradient (Provis, van Driel, Billson, \& Russell, 1985). Mitosis in the fovea ceases by 14 weeks' postmenstrual age (PMA) but continues in the far periphery to at least 29 weeks' PMA (Provis, et al., 1985). At 2022 weeks' PMA, central and mid peripheral rods and cones are beginning to differentiate, and by 28 weeks all cell layers are present (Provis, et al., 1985). The migration of cone photoreceptors toward the foveal pit and the movement of ganglion cells away from the foveal pit continues until beyond 57 weeks' PMA. Because DHA is important for retinal cell development and preterm infants are DHA deplete during the last trimester, the visual system for many of these children may be adversely affected.

The cones of the retina, except for foveal cones, are morphologically more mature than rods at the time of birth (Birch, Birch, Petrig, \& Uauy, 1990; Birch \& O'Connor, 2001; Hendrickson \& Drucker, 1992). Rods also experience significant changes postnatally (Uauy, Birch, Birch, Tyson, \& Hoffman, 1990). Cultured rat retinal photoreceptors free from fatty acid undergo selective degeneration followed by apoptosis, but when DHA is added to the culture it increases its proportion in neuronal lipids and prevents the degeneration of photoreceptors (Rotstein, Aveldano, Barrantes, \& Politi, 1996). Consistent with these findings, studies on rats and primates have demonstrated low levels of retinal and brain DHA when fed diets deficient in n-3 fatty acids (Lamptey \& Walker, 1978; 
Neuringer, et al., 1986; Wheeler, Benolken, \& Anderson, 1975), showing the greatest effect postnatally compared with prenatally (Neuringer, et al., 1986). The brain and retina of human infants is less developed than rhesus monkeys, thus it has been speculated that postnatal deprivation of DHA might be especially problematic for human infants (Neuringer, et al., 1986). Preterm infants are developing within an atypical environment and during a time when DHA accumulation is at its greatest, therefore it stands to reason that an immature visual system is particularly vulnerable to low levels of DHA. Indeed, the maturation of rod sensitivity appears to be slowed by preterm birth, likely influenced by environmental factors which adversely affect the development of photoreceptors, including nutritional insufficiency, such as DHA, and retinal vascularity (Hamilton, Bradnam, Dudgeon, \& Mactier, 2008). The implication appears to be that less mature structures may be at greater risk of dietary deprivation of DHA, resulting in specific functional consequences, which may be particularly relevant for preterm infants

The functional distinctions of the visual pathways are usually described from the cortical regions of the brain, however there are also several functionally distinct populations of retinal ganglion cells. Of particular interest are the $\mathrm{P}$ and $\mathrm{M}$ ganglion cells, so called as most $\mathrm{M}$ retinal ganglion cell axons project to the magnocellular layers of the lateral geniculate nucleus (LGN), whereas the P ganglion cells project to the parvocellular layers (Maunsell, Nealey, \& DePriest, 1990). M and P ganglion cells differ in terms of morphology and thus also have different functional properties. For example, $M$ cells are fast responding and specialised in processing low spatial frequency information, such as the general size and shape of an object. Because they respond transiently to the presentation of visual stimuli $\mathrm{M}$ cells are important for motion perception, spatial relationships, and directing actions (Merigan \& Maunsell, 1990; A. S. Mitchell, Baxter, \& Gaffan, 2007; Tanaka, 1976). P cells respond in a sustained fashion and are specialised for processing high spatial frequency information, such as discrimination of colour, texture, fine shape, and pattern (Livingstone \& Hubel, 1988; Maunsell, et al., 1990). The information from the magnocellular and parvocellular layers of the LGN remains separate at least in the initial stages of cortical processing; for this reason the terms magnocellular stream and parvocellular stream are often used to signify the pathways that transmit information derived from $\mathrm{M}$ and $\mathrm{P}$ ganglion cells. Importantly, $\mathrm{M}$ cells require high amounts of polyunsaturated fatty acids to function efficiently (Ahmad, Moriguchi, \& Salem, 2002; Stein, 2001) and thus visual functions reliant on efficiency are potentially affected by inadequate DHA concentrations following preterm birth. Additionally, DHA can be protective against oxidative and hypoxic stress-induced cell damage in retinal ganglion cells (Shimazawa, Nakajima, Mashima, \& Hara, 2009). This point is crucial 
considering fluctuations in cerebral blood flow and hypoxaemic insults during apnoeic episodes are common in preterm infants.

There may be far reaching consequences on the visual system for preterm infants who receive inadequate DHA during postnatal development (Bourgeois, Jastreboff, \& Rakic, 1989; Mirabella, Kjaer, Norcia, Good, \& Madan, 2006; Wiesel, 1982). Beyond the occipital cortex the visual system divides into two hierarchically arranged and anatomically and functionally separate pathways; the dorsal and ventral streams (Goodale \& Milner, 1992; Livingstone \& Hubel, 1988). Visual information from the magnocellular pathway remains relatively segregated at the level of the primary visual cortex, as well as predominates the innervations of the dorsal stream, such as areas V2, V3, and V5 (V5 is also called the middle temporal area (MT)) (Goodale \& Milner, 1992; Maunsell, et al., 1990; Mendes et al., 2005; Morand et al., 2000). Anatomical, physiological, and behavioural studies have demonstrated strong links between functions of the magnocellular and dorsal stream and between the parvocellular and ventral stream (Heinrich, 2007; Kubova, Kuba, Spekreijse, \& Blakemore, 1995; Merigan \& Maunsell, 1993). As DHA appears to be particularly important for M cells, inadequate dietary intake of DHA may have specific ramifications for visual functions subsumed by the magnocellular/dorsal stream.

\section{Functional Assessment Considerations}

Despite physiological evidence which has highlighted the importance of DHA for specific structures and processes important for vision, research to date has focussed on only a narrow range of visual outcomes and thus our understanding of the role of DHA on the development of the visual system is limited. In order to truly understand the influence of DHA on the developing visual system a comprehensive range of assessment tools are required. This may have significant ramifications for children with visual impairments, especially those born preterm.

The mechanisms related to visual impairment in preterm children are likely to be multi-factorial, including DHA insufficiency, exposure to early visual stimuli, and brain injury. However, the specific role of DHA deficiency may be partially untangled by studying different visual functions, as their developmental trajectories differ (Madan, Jan, \& Good, 2005) and some functions may be more vulnerable to DHA insufficiency. For example, visual acuity is measured with high contrast (e.g. logMAR visual acuity chart), and thus it is not representative of many visual situations. In contrast, contrast sensitivity, measures the ability to detect slight changes in luminance across space (Mirabella, et al., 2006), is a measure of the minimum contrast required to identify a stimulus 
against its background (A. R. O'Connor \& Fielder, 2007) and can provide additional information about the functional ability of the visual system. Low spatial frequencies (e.g. coarse scale information) develop more rapidly and over a shorter time course than high spatial frequencies (e.g. fine scale details) (Norcia, Tyler, \& Hamer, 1990) thus low spatial frequencies may be more vulnerable to DHA insufficiency, particularly in preterm infants during the neonatal period. Grating acuity, which is the ability to distinguish the elements of a fine grating composed of alternating dark and light stripes, shows slower development, and thresholds are maximal when foveal architecture is fully developed at around 5 to 8 years of age (Madan, et al., 2005; Mirabella, et al., 2006).

Because development of grating acuity has a protracted time course, adequate intake of dietary DHA may be important throughout early school-age years. Vernier acuity on the other hand, which measures the minimum offset that can be detected between two line segments (Mirabella, et al., 2006), requires significant cortical input to obtain maximal thresholds (Skoczenski \& Norcia, 1999) and thus inadequate DHA may affect the initial rapid maturation of vernier acuity over the first few months of life (Manny \& Klein, 1984; Shimojo, Birch, Gwiazda, \& Held, 1984; Skoczenski \& Norcia, 1999). Given the potential role DHA has for the visual system structures, broader evaluation, beyond measures of visual acuity, should be considered in future investigations, including contrast sensitivity and vernier acuity.

Studies evaluating the effect of DHA on visual processing, in both full term and preterm infants, have used either visual evoked potentials (VEP) or grating acuity, both of which assess very low level visual function (Madan, et al., 2005). The visual system is complex and a single measure is unlikely to be an accurate representation of functional vision as a whole. For example, grating acuity is affected very differently from either contrast sensitivity or vernier (positional) acuity in patients with amblyopia (McKee, Levi, \& Movshon, 2003). Specifically, amblyopia has little effect on low spatial frequency contrast sensitivity, a moderate effect on grating acuity, and a strong effect on vernier acuity (McKee, et al., 2003). Amblyopia is the result of abnormal visual experience during early postnatal development and is usually associated with unequal refractive error in the two eyes (Levi \& Klein, 1982; Levi \& Klein, 1992). Research utilising VEP suggests that the visual cortex may undergo accelerated maturation in preterm birth (Madan, et al., 2005) raising important questions about the long-term relevance of studies that have reported improved VEP outcomes following supplementation with DHA. For example, this may suggest that evaluating visual functioning via VEP may be more useful and relevant later in development. These functional and developmental considerations highlight the importance of evaluating the effect of DHA supplementation on different aspects of functional vision and beyond the first months of life. The neural mechanisms 
underlying dietary effects on visual acuity for preterm infants are not well understood thus examining additional measures of visual function would help to clarify the extent and nature of the effects of DHA on the developing visual system.

Because rods have different functional properties and are more adversely affected by inadequate DHA than cone cells, there may be specific functional consequences. Rod cells are located mostly in the peripheral part of the retina; they are about 500 times more sensitive to light than cone cells, enable night vision and are more sensitive to motion than cone cells. Consequently, visual functions such as contrast sensitivity, perception of motion, and visual fields may be influenced by DHA supplementation, in addition to visual acuity. This premise is supported by research on animals; in rats, deficient n-3 fatty acids results in decreased amplitude of the electroretinogram (Wheeler, et al., 1975) and impairment in the ability to learn a visual discrimination task (Lamptey \& Walker, 1978), whereas in primates the deficient animals have reduced visual acuity (Neuringer, et al., 1986) and an abnormal electroretinograph (Birch, et al., 1992). Importantly, several studies following up infants born preterm have reported difficulties in numerous sensory functions (Cioni, et al., 2000; Cooke, et al., 2004; Dowdeswell, Slater, Broomhall, \& Tripp, 1995; Jakobson, et al., 2006; Pavlova, et al., 2006; Powls, et al., 1997; Stephenson, et al., 2007).

\section{Dorsal Visual Stream \& DHA}

Several authors have suggested that preterm infants display a particular vulnerability of dorsal stream processing (Atkinson \& Braddick, 2007; Jakobson, et al., 2006; Olsen et al., 1998; Pavlova, et al., 2006). For example, development of the motion processing system, a major attribute of the dorsal stream, which typically develops between 2 to 3 months, is delayed in preterm infants by approximately 4 weeks (Atkinson \& Braddick, 2007). Additionally, several other studies have reported that preterm infants exhibit a clustering of deficits that rely on accurate processing within the dorsal steam, such as spatial memory, visual motor integration, visuospatial manipulation, and spatial navigation (Atkinson \& Braddick, 2007; Olsen, et al., 1998; Pavlova, et al., 2006; Pavlova, et al., 2007). The reason preterm children may have a particular vulnerability to dorsal stream functioning is unclear, as MRI studies have shown diffuse white matter injury affecting both the dorsal (occipito-parietal pathway) and ventral streams (occipito-temporal pathway) (Hagberg, Peebles, \& Mallard, 2002; Huppi, 2004). Importantly however, it has been shown that M cells need high amounts of polyunsaturated fatty acids to preserve their membrane flexibility crucial for allowing physiological processes, which underlie $\mathrm{M}$ cells transient sensitivity important for detecting motion (Stein, 2001). Thus, damaged or inefficient M cells in the magnocellular pathway and dorsal 
stream may affect processing within these pathways and in turn functions subsumed by these regions/pathways. The notion that dorsal stream processing may be related to DHA deficiency is supported by dyslexia research. Numerous studies report that dyslexics who have clinical signs of essential fatty acid deficiency (Richardson et al., 2000; K. E. Taylor et al., 2000), demonstrate a specific vulnerability to magnocellular dysfunction. This has been consistently shown by testing sensitivity to moving stimuli. Motion engages not only the peripheral $\mathrm{M}$ cells within the occipital cortex but also parts of the dorsal stream such as up to at least area V5/MT in the extrastriate cortex.

Stereopsis, which is the perception of depth achieved from two slightly different images that fall on the retinas of the two eyes, has also been speculated to be a unique attribute of the magnocellular and dorsal processing stream (Backus, Fleet, Parker, \& Heeger, 2001; Nishida et al., 2001; Schechter et al., 2006). Stereopsis is dependent on equal visual acuity by the two eyes, normal eye alignment, and history of binocular experience. Stereopsis plays a vital role in many visual motor activities including reaching, manipulation of objects, motion perception, and spatial navigation within varying environments (Coren \& Hakstian, 1996; Jakobson, et al., 2006). Preterm children exhibit more impairments in stereopsis than children born at term (e.g. (Cooke, et al., 2004; Dowdeswell, et al., 1995; Stephenson, et al., 2007)), which may partly explain the increased incidence of impaired motor performance in preterm groups, particularly those without focal white matter lesions. According to Banks, Aslin, and Letson (1975) the critical periods for susceptibility of binocular vision are between 3 and 6 months, and between 12 and 20 months, potentially implicating a critical role of DHA in the neonatal period. DHA insufficiency could have a two-fold effect on stereoacuity and the subsequent processing reliant on its accuracy. Indeed, there is some evidence to suggest that stereopsis is enhanced in children who have been breast-fed compared with those infants who were formula-fed (Williams et al., 2001), which may reflect lower concentrations of DHA in infant formula in comparison with maternal breast-milk.

\section{Global and local form processing and DHA}

Global precedence occurs when general information is processed without interference from local information (Antes \& Mann, 1984). A common visual stimulus employed to investigate levels of visual analysis is the Navon stimulus (Navon, 1981), which for example would present a large $\mathrm{H}$ (global) consisting of small Es (local)(see figure 1 for an example of a Navon stimulus). If the individual preferentially identifies the $\mathrm{H}$ over the Es the visual analysis is dominated by global information. Global precedence is related to spatial frequency, in that the large $\mathrm{H}$ is processed by 
low spatial frequency mechanisms, while the Es are processed by high spatial frequency visual mechanisms (Antes \& Mann, 1984). It has been argued by Hughes (1986) that global precedence is reliant on the speed advantage of the coarse scale information, which, when abolished, also abolished the global precedence. There has only been the one study examining the visual analysis of global and local information in preterm children; Santos et al. (2010) reported that preterm children demonstrated an atypical pattern of visual processing, in that they preferentially relied on local information rather than on a global analysis when performing a visual perceptual task. As such, preterm children may display a local precedence. One explanation for this finding is that inadequate DHA in the neonatal period affects the development of the magnocellular/dorsal pathway that consequently abolishes the "typical" speed advantage of low spatial frequency information usually associated with visual processing. This may have ramifications for visual perception and visual learning. For example, low spatial frequency information is important for face emotion recognition (Butler et al., 2009).

\section{Visual Perception and DHA}

If DHA deficiency is found to be associated with visual sensory outcomes such as visual acuity, then one may expect a secondary influence on visual perception that must, in part, rely on the accuracy of early visual processing. Visual perception deficiencies are common in preterm children both with (Ito et al., 1996; Koeda \& Takeshita, 1992; Ploner et al., 1999) and without (Davis, Burns, Wilkerson, \& Steichen, 2005; Feder et al., 2005; Hard, Niklasson, Svensson, \& Hellstrom, 2000; McGrath \& Sullivan, 2002) focal brain injury. Preterm children have difficulties with a range of visual perceptual tasks, ranging from basic visual discrimination to more complex visual closure and figure-ground tasks. Perceptual closure processes and perception of figure-ground are related to specific activation of the (right greater than left) lateral occipital complex. The lateral occipital complex has also been implicated in other aspects of object perception, such as visual discrimination. Further, perceptual closure tests require identification of whole figures from incomplete versions of various forms (Wasserstein, Barr, Zappulla, \& Rock, 2004). Perceptual closure and facial discrimination tests have classically been used as critical measures of right hemisphere "Gestalt" functioning (e.g. Benton \& Van Allen, 1968; Bogen, De Zure, Tenhouten, \& Marsh, 1972; De Renzi, Faglioni, \& Spinnler, 1968; Warrington \& James, 1967). Deficient visual perception has been correlated with visual acuity (van den Hout et al., 2000), strabismus (Koeda \& Takeshita, 1992), and amblyopia (Koeda \& Takeshita, 1992) in preterm children, however due to the paucity of studies testing the relationship between 
visual function and visual perception it is less clear whether these deficiencies can be attributed to sensory abnormalities.

In summary, a broader range of neuropsychological measures should be considered when clinicians evaluate children who are born preterm. Whilst it is not always practical to assess some of the visual functions mentioned above, screening for basic visual functions such as visual acuity and stereopsis are relatively simple and quick to administer. Difficulties with contrast sensitivity, depth perception, motion and global processing may have secondary consequences, which are worth considering when designing the assessment protocol, such as visual perception, visual motor integration, and spatial navigation. Further research may elucidate other important relationships between DHA, visual processing and multifactorial cognitive skills that could better inform clinical neuropsychologists.

\section{DHA supplementation in Humans}

Animal research served as a good basis for DHA supplementation in human infants by documenting the effect of inadequate DHA for structures important for visual processing (Lamptey \& Walker, 1978; Neuringer, et al., 1986; Wheeler, et al., 1975). Preliminary evidence of randomised controlled trials (RCTs) involving formula-fed term and preterm infants provides some initial support for the concept that inadequate dietary intake of DHA early in life is related to adverse visual processing outcomes in preterm children (Birch, et al., 1992; Carlson, Werkman, Rhodes, \& Tolley, 1993; Carlson, Werkman, \& Tolley, 1996; D. L. O'Connor, et al., 2001; Smithers, et al., 2008).

There have been a number of trials that have evaluated the short term effect of DHA supplementation on cognitive and visual functioning in both term and preterm infants. These are typically difficult to compare as they differ in the type and dose of fatty acid, duration and commencement of supplementation, age of subjects when assessed (Eilander, Hundscheid, Osendarp, Transler, \& Zock, 2007), and outcome measures. The major outcome measures used to assess the effect of DHA supplementation on visual development, reflected by retinal and cortical visual function, have been electroretinography (ERG) and visual acuity as assessed by visual evoked potential (VEP) and/or preferential looking techniques. The outcomes reported in RCTs involving term infants have varied between studies; some have demonstrated a benefit for visual function (Birch et al., 2010; Birch et al., 2002; Carlson, Ford, Werkman, Peeples, \& Koo, 1996; Hoffman et al., 2003; Makrides, Neumann, Simmer, Pater, \& Gibson, 1995), while others show no difference (Auestad et al., 1997; Jensen et al., 2010; Jorgensen, Hernell, Lund, Holmer, \& Michaelsen, 1996). RCTs involving preterm infants have demonstrated more consistent benefits for visual acuity 
following DHA supplementation, at least over the first six months of life (e.g. (Birch, et al., 1992; Carlson, et al., 1993; Carlson, Werkman, et al., 1996; D. L. O'Connor, et al., 2001; Smithers, et al., 2008).

A meta-analysis conducted by SanGiovanni et al. (2000) aimed to determine the combined estimates of visual resolution acuity differences between preterm infants who received different compositions and ratios of essential fatty acids and DHA. They reported that there were significant differences in visual resolution acuity at 2 and 4 months of age between preterm infants fed formula supplemented with DHA compared with preterm infants not supplemented with DHA (SanGiovanni, Parra-Cabrera, Colditz, Berkey, \& Dwyer, 2000). A number of Cochrane reviews have also been undertaken, which consistently conclude that DHA supplementation of infant formula increases the rate of visual maturation in preterm infants but ascribe no clear long-term benefits greater than 6 months (Schulzke, Patole, \& Simmer, 2011; Simmer, 2000).

Human brain composition studies have provided valuable information about the effect of deficient DHA on the brain and retina. For example, term infants fed formula without DHA who died suddenly have been found to have lower DHA concentrations in their frontal cortex, in comparison with term infants who were breastfed and consequently received a dietary source of DHA (Makrides, et al., 1994). Further, the brain and retinal DHA composition of preterm infants at matched ages is lower than that of term infants regardless of feeding mode (Martinez, 1992). Importantly, supplementation with DHA during pregnancy has been shown to increase the level of this fatty acid in both maternal and infants' erythrocyte cell membranes, umbilical blood levels, and infant plasma levels (Birch, et al., 1998; Connor, et al., 1996; Le, et al., 2009; Smuts, et al., 2003; van Houwelingen, et al., 1995; Velzing-Aarts, et al., 2001). In turn, and according to a randomised trial involving healthy full term infants, better visual acuity and stereoacuity at 17 weeks of age are correlated with higher concentrations of DHA in plasma, and better visual acuity at 52 weeks of age is associated with higher concentrations of DHA in plasma and red blood cells (Birch, et al., 1998).

Although there appears to be some evidence that preterm infants benefit from diets supplemented with DHA very early in visual development, there are a number of methodological limitations that raise important questions of the validity and relevance of previous findings, and likely explains the inconsistency of results across studies, in particular beyond 6 months of age. Firstly, previous studies have used formula for supplementation rather than breast milk. Breast milk is the milk-feedof-choice for the clinical management of preterm infants in the neonatal intensive care unit and has 
several nutritional advantages, including decreased risks of necrotizing enterocolitis (Lee \& Polin, 2003; Sisk, Lovelady, Dillard, Gruber, \& O'Shea, 2007) and sepsis (Furman, Taylor, Minich, \& Hack, 2003; Hylander, Strobino, \& Dhanireddy, 1998), and improved motor and cognitive development (Lucas, Morley, Cole, Lister, \& Leeson-Payne, 1992; Vohr et al., 2006). Secondly, most trials have tested low concentrations of DHA that are comparable with the breast milk of women consuming a Western-style diet, which is between approximately 0.2 and $0.3 \%$ of total fatty acids (Gibson, Chen, \& Makrides, 2001). However the quantity of DHA an infant would receive from this dose is well below what the fetus accrues during the last trimester (Makrides, et al., 1994; Martinez, 1992). It has been estimated that 1\% DHA emulates the in utero accretion of DHA (Makrides, et al., 1994; Martinez, 1992) suggesting that the concentration of DHA used in previous trials is inadequate, thus failing to either increase the level of DHA in the retina and cortex and/or is insufficient to influence functional outcomes. Consistent with this view, slightly higher supplemental concentrations of DHA, up to $0.6 \%$, have been more likely to result in positive outcomes concerning cognitive and motor development for preterm infants (Clandinin et al., 1980; Fewtrell et al., 2004). Further, there is some evidence of a dose-response relationship between dietary DHA concentration and neural function; Uauy et al. (2003) correlated the effect size in visual acuity against DHA dose and found that the higher the DHA content the greater the effect (Uauy, Hoffman, Mena, Llanos, \& Birch, 2003). These studies suggest that the level of DHA supplementation is an important factor in achieving improved outcomes. It may be postulated that trials with experimental formulas close to the worldwide human milk average are more likely to yield functional benefits attributable to DHA than those providing only relatively low-dose supplementation. Despite these methodological limitations there is a general trend indicating that supplementation with DHA has a positive effect on visual function.

A study which overcomes many of the limitations outlined above has shown partial benefits for preterm infants fed high dose DHA ( $1 \%$ of total fatty acids) breast milk in comparison with preterm infants fed standard DHA (approximately $0.3 \%$ total fatty acids). Beneficial differences were documented in early cognitive development (Makrides, Gibson, \& McPhee, 2009), hay fever (Manley et al., 2011), and need for supplemental oxygen at 36 weeks' corrected age (Manley, et al., 2011). This study also reported that preterm infants fed milk with high dose DHA concentrations had improved visual acuity at 4 months corrected age compared with infants receiving standard DHA doses (Smithers, et al., 2008). The long-term significance of DHA supplementation on visual acuity and other visual functions is unknown. 


\section{Conclusions and future directions}

Preterm children are at risk for a number of visual impairments, including difficulties with visual acuity, contrast sensitivity, stereopsis, and visual perception, which are important for a range of more complex and adaptive skills reliant of visual information. Despite the relatively high incidence of visual impairments in this group there are no good predictors that would allow early identification of those at risk for adverse outcomes. Several lines of evidence suggest that DHA supplementation for preterm infants may improve outcomes in this area. For example, DHA is important for a number of visual processes, such as photo-transduction, regeneration of rhodopsin, and maturation of the cortical visual pathway; animals fed diets deficient in DHA demonstrate impaired visual acuity and visual learning; and human studies show short-term benefits for visual acuity following supplementation with DHA.

Future studies should address the significant research gaps, such as evaluating the effect of DHA supplementation on functions specifically related to the structural and physiological processes reliant on adequate DHA concentrations. Despite the possible link between inadequate DHA and specific visual structures and functions there is a lack of empirical evidence supporting this association. Thus well-defined studies that combine the knowledge we have about the structures and functions of the visual system that are reliant upon adequate DHA concentrations, with specific functional outcomes dependent on their integrity, may elucidate important associations between preterm birth, DHA, and visual processing. For example, it could be beneficial to explore the relationship between DHA supplementation and visual functions reliant on the efficiency of $\mathrm{M}$ cells, such as motion processing, contrast sensitivity, and stereopsis. Exploring the relationship between DHA supplementation and its possible role in influencing the documented dorsal stream vulnerability commonly described in preterm infants also warrants further attention. Further, research examining the long-term visual outcomes of DHA supplementation beyond 18 months of age in preterm children is a major research gap that requires greater follow up.

The clinical significance of DHA deficiency is substantial if it can be demonstrated to be associated with the development of visual processes. Early intervention comprising DHA supplementation would be relatively inexpensive and easy to prescribe. The possible short- and long-term benefits, especially for very preterm children, include improved quality of life, and reduced follow-up, medical care, and special education costs. 


\section{Acknowledgements}

This work was supported by the National Health and Medical Research Council (Senior Research Fellowship 628371 to P.J.A, 565000 to M. M.) and the Victorian Government's Operational Infrastructure Support Program. 


\section{References}

Ahmad, A., Moriguchi, T., \& Salem, N. (2002). Decrease in neuron size in docosahexaenoic aciddeficient brain. Pediatric Neurology, 26, 210-218.

Anderson, P. J., \& Doyle, L. W. (2003). Neurobehavioral outcomes of school-age children born extremely low birth weight or very preterm in the 1990s. Jama, 289, 3264-3272.

Anderson, R. E., \& Risk, M. (1974). Lipids of ocular tissues. IX. The phospholipids of frog photoreceptor membranes. Vision Research, 14, 129-131.

Antes, J. R., \& Mann, S. W. (1984). Global-local precedence in picture processing. Psychological Research, 46, 247-259.

Atkinson, J., \& Braddick, O. (2007). Visual and visuocognitive development in children born very prematurely. Progress in Brain Research, 164, 123-149.

Auestad, N., Montalto, M. B., Hall, R. T., Fitzgerald, K. M., Wheeler, R. E., Connor, W. E., et al. (1997). Visual acuity, erythrocyte fatty acid composition, and growth in term infants fed formulas with long chain polyunsaturated fatty acids for one year. Ross Pediatric Lipid Study. Pediatric Research, 41, 1-10.

Aveldano, M. I. (1988). Phospholipid species containing long and very long polyenoic fatty acids remain with rhodopsin after hexane extraction of photoreceptor membranes. Biochemistry, $27,1229-1239$.

Aylward, G. P. (2002). Cognitive and neuropsychological outcomes: more than IQ scores. Ment Retard Dev Disabil Res Rev, 8, 234-240.

Aylward, G. P. (2005). Neurodevelopmental outcomes of infants born prematurely. J Dev Behav Pediatr, 26, 286-294.

Backus, B. T., Fleet, D. J., Parker, A. J., \& Heeger, D. J. (2001). Human cortical activity correlates with stereoscopic depth perception. Journal of Neurophysiology, 86, 2054-2068.

Bhutta, A. T., Cleves, M. A., Casey, P. H., Cradock, M. M., \& Anand, K. J. S. (2002). Cognitive and behavioral outcomes of school-aged children who were born preterm: a meta-analysis. Jama, 288, 728-737.

Birch, E. E., Birch, D., Petrig, B., \& Uauy, R. D. (1990). Retinal and cortical function of infants at 36 and 57 weeks post-conception. Clinical Vision Science, 5, 363-373.

Birch, E. E., Birch, D. G., Hoffman, D. R., \& Uauy, R. D. (1992). Dietary essential fatty acid supply and visual acuity development. Investigative Ophthalmology and Visual Science, 33, 3242-3253.

Birch, E. E., Carlson, S. E., Hoffman, D. R., Fitzgerald-Gustafson, K. M., Fu, V. L. N., Drover, J. R., et al. (2010). The DIAMOND (DHA Intake And Measurement Of Neural Development) Study: a 
double-masked, randomized controlled clinical trial of the maturation of infant visual acuity as a function of the dietary level of docosahexaenoic acid. American Journal of Clinical Nutrition, 91, 848-859.

Birch, E. E., Hoffman, D. R., Castaneda, Y. S., Fawcett, S. L., Birch, D. G., \& Uauy, R. D. (2002). A randomized controlled trial of long-chain polyunsaturated fatty acid supplementation of formula in term infants after weaning at 6 wk of age. American Journal of Clinical Nutrition, 75, 570-580.

Birch, E. E., Hoffman, D. R., Uauy, R. D., Birch, D. G., \& Prestidge, C. (1998). Visual acuity and the essentiality of docosahexaenoic acid and arachidonic acid in the diet of term infants. Pediatric Research, 44, 201-209.

Birch, E. E., \& O'Connor, A. R. (2001). Preterm birth and visual development. Semin Neonatol, 6, 487497.

Bourgeois, J. P., Jastreboff, P. J., \& Rakic, P. (1989). Synaptogenesis in visual cortex of normal and preterm monkeys: evidence for intrinsic regulation of synaptic overproduction. Proceedings of the National Academy of Sciences of the United States of America, 86, 4297-4301.

Brand, A., Bauer, N. G., Hallott, A., Goldbaum, O., Ghebremeskel, K., Reifen, R., et al. (2010). Membrane lipid modification by polyunsaturated fatty acids sensitizes oligodendroglial OLN93 cells against oxidative stress and promotes up-regulation of heme oxygenase-1 (HSP32). Journal of Neurochemistry, 113, 465-476.

Buksh, M. J., Dai, S., \& Kuschel, C. A. (2008). AP-ROP in an infant with minimal oxygen exposure. Journal of Paediatrics and Child Health, 44, 228-230. doi: 10.1111/j.1440-1754.2008.01287.x

Bush, R. A., Malnoe, A., Reme, C. E., \& Williams, T. P. (1994). Dietary deficiency of N-3 fatty acids alters rhodopsin content and function in the rat retina. Investigative Ophthalmology and Visual Science, 35, 91-100.

Butler, P. D., Abeles, I. Y., Weiskopf, N. G., Tambini, A., Jalbrzikowski, M., Legatt, M. E., et al. (2009). Sensory contributions to impaired emotion processing in schizophrenia. Schizophrenia Bulletin, 35, 1095-1107.

Carlson, S. E., Ford, A. J., Werkman, S. H., Peeples, J. M., \& Koo, W. W. (1996). Visual acuity and fatty acid status of term infants fed human milk and formulas with and without docosahexaenoate and arachidonate from egg yolk lecithin. Pediatric Research, 39, 882-888.

Carlson, S. E., Werkman, S. H., Rhodes, P. G., \& Tolley, E. A. (1993). Visual-acuity development in healthy preterm infants: effect of marine-oil supplementation. American Journal of Clinical Nutrition, 58, 35-42. 
Carlson, S. E., Werkman, S. H., \& Tolley, E. A. (1996). Effect of long-chain n-3 fatty acid supplementation on visual acuity and growth of preterm infants with and without bronchopulmonary dysplasia. American Journal of Clinical Nutrition, 63, 687-697.

Chen, Y., Houghton, L. A., Brenna, J. T., \& Noy, N. (1996). Docosahexaenoic acid modulates the interactions of the interphotoreceptor retinoid-binding protein with 11-cis-retinal. Journal of Biological Chemistry, 271, 20507-20515.

Cioni, G., Bertuccelli, B., Boldrini, A., Canapicchi, R., Fazzi, B., Guzzetta, A., et al. (2000). Correlation between visual function, neurodevelopmental outcome, and magnetic resonance imaging findings in infants with periventricular leucomalacia. Arch Dis Child Fetal Neonatal Ed, 82, 134-140.

Clandinin, M. T., Chappell, J. E., Leong, S., Heim, T., Swyer, P. R., \& Chance, G. W. (1980). Intrauterine fatty acid accretion rates in human brain: implications for fatty acid requirements. Early Human Development, 4, 121-129.

Connor, W. E., Lowensohn, R., \& Hatcher, L. (1996). Increased docosahexaenoic acid levels in human newborn infants by administration of sardines and fish oil during pregnancy. Lipids, 31 Suppl, S183-187.

Cooke, R. W., Foulder-Hughes, L., Newsham, D., \& Clarke, D. (2004). Ophthalmic impairment at 7 years of age in children born very preterm. Arch Dis Child Fetal Neonatal Ed, 89, 249-253.

Coren, S., \& Hakstian, R. (1996). Screening for stereopsis without the use of technical equipment: scale development and cross-validation. Int J Epidemiol, 25, 146-151.

Crawford, M. A., Costeloe, K., Ghebremeskel, K., Phylactos, A., Skirvin, L., \& Stacey, F. (1997). Are deficits of arachidonic and docosahexaenoic acids responsible for the neural and vascular complications of preterm babies? American Journal of Clinical Nutrition, 66, 1032S-1041S.

Davis, D. W., Burns, B. M., Wilkerson, S. A., \& Steichen, J. J. (2005). Visual perceptual skills in children born with very low birth weights. J Pediatr Health Care, 19, 363-368.

Decsi, T., \& Koletzko, B. (1994). Polyunsaturated fatty acids in infant nutrition. Acta Paediatrica. Supplement, 83, 31-37.

Dowdeswell, H. J., Slater, A. M., Broomhall, J., \& Tripp, J. (1995). Visual deficits in children born at less than 32 weeks' gestation with and without major ocular pathology and cerebral damage. British Journal of Ophthalmology, 79, 447-452.

Downie, A. L. S., Jakobson, L. S., Frisk, V., \& Ushycky, I. (2003). Periventricular brain injury, visual motion processing, and reading and spelling abilities in children who were extremely low birthweight. Journal of International Neuropsychology Society, 9, 440-449. 
Eilander, A., Hundscheid, D. C., Osendarp, S. J., Transler, C., \& Zock, P. L. (2007). Effects of n-3 long chain polyunsaturated fatty acid supplementation on visual and cognitive development throughout childhood: a review of human studies. Prostaglandins Leukotrienes and Essential Fatty Acids, 76, 189-203.

Eken, P., de Vries, L. S., van der Graaf, Y., Meiners, L. C., \& van Nieuwenhuizen, O. (1995). Haemorrhagic-ischaemic lesions of the neonatal brain: correlation between cerebral visual impairment, neurodevelopmental outcome and MRI in infancy. Developmental Medicine and Child Neurology, 37, 41-55.

Evensen, K. A. I., Lindqvist, S., Indredavik, M. S., Skranes, J., Brubakk, A.-M., \& Vik, T. (2009). Do visual impairments affect risk of motor problems in preterm and term low birth weight adolescents? Eur J Paediatr Neurol, 13, 47-56.

Faldella, G., Govoni, M., Alessandroni, R., Marchiani, E., Salvioli, G. P., Biagi, P. L., et al. (1996). Visual evoked potentials and dietary long chain polyunsaturated fatty acids in preterm infants. Archives of Disease in Childhood. Fetal and Neonatal Edition, 75, F108-112.

Feder, K. P., Majnemer, A., Bourbonnais, D., Platt, R., Blayney, M., \& Synnes, A. (2005). Handwriting performance in preterm children compared with term peers at age 6 to 7 years. Developmental Medicine and Child Neurology, 47, 163-170.

Fewtrell, M. S., Abbott, R. A., Kennedy, K., Singhal, A., Morley, R., Caine, E., et al. (2004). Randomized, double-blind trial of long-chain polyunsaturated fatty acid supplementation with fish oil and borage oil in preterm infants. Journal of Pediatrics, 144, 471-479.

Fielder, A. R. (1998). The impact of low birth weight on the visual pathway. Br J Ophthalmol, 82, 1-2. Furman, L., Taylor, G., Minich, N., \& Hack, M. (2003). The effect of maternal milk on neonatal morbidity of very low-birth-weight infants. Archives of Pediatrics and Adolescent Medicine, $157,66-71$.

Gibson, R. A., Chen, W., \& Makrides, M. (2001). Randomized trials with polyunsaturated fatty acid interventions in preterm and term infants: functional and clinical outcomes. Lipids, 36, 873883.

Goodale, M. A., \& Milner, A. D. (1992). Separate visual pathways for perception and action. Trends Neurosci, 15, 20-25.

Grisham, D., Powers, M., \& Riles, P. (2007). Visual skills of poor readers in high school. Optometry, 78, 542-549.

Hack, M., Taylor, H. G., Drotar, D., Schluchter, M., Cartar, L., Andreias, L., et al. (2005). Chronic conditions, functional limitations, and special health care needs of school-aged children born with extremely low-birth-weight in the 1990s. Jama, 294, 318-325. 
Hagberg, H., Peebles, D., \& Mallard, C. (2002). Models of white matter injury: Comparison of infectious, hypoxic-ischemic, and excitotoxic insults. Mental Retardation and Developmental Disabilities Research Reviews, 8, 30-38.

Hamilton, R., Bradnam, M. S., Dudgeon, J., \& Mactier, H. (2008). Maturation of rod function in preterm infants with and without retinopathy of prematurity. Journal of Pediatrics, 153, 605611.

Hard, A. L., Niklasson, A., Svensson, E., \& Hellstrom, A. (2000). Visual function in school-aged children born before 29 weeks of gestation: a population-based study. Developmental Medicine and Child Neurology, 42, 100-105.

Heinrich, S. P. (2007). A primer on motion visual evoked potentials. Documenta Ophthalmologica, 114, 83-105.

Hendrickson, A., \& Drucker, D. (1992). The development of parafoveal and mid-peripheral human retina. Behavioural Brain Research, 49, 21-31.

Hoffman, D. R., Birch, E. E., Castaneda, Y. S., Fawcett, S. L., Wheaton, D. H., Birch, D. G., et al. (2003). Visual function in breast-fed term infants weaned to formula with or without long-chain polyunsaturates at 4 to 6 months: a randomized clinical trial. Journal of Pediatrics, 142, 669677.

Hollenberg, M. J., \& Spira, A. W. (1973). Human retinal development: ultrastructure of the outer retina. American Journal of Anatomy, 137, 357-385.

Hornstra, G., Al, M. D., van Houwelingen, A. C., \& Foreman-van Drongelen, M. M. (1995). Essential fatty acids in pregnancy and early human development. European Journal of Obstetrics, Gynecology, and Reproductive Biology, 61, 57-62.

Huppi, P. S. (2004). Immature white matter lesions in the premature infant. J Pediatr, 145, 575-578.

Huppi, P. S., Warfield, S., Kikinis, R., Barnes, P. D., Zientara, G. P., Jolesz, F. A., et al. (1998). Quantitative magnetic resonance imaging of brain development in premature and mature newborns. Annals of Neurology, 43, 224-235.

Hylander, M. A., Strobino, D. M., \& Dhanireddy, R. (1998). Human milk feedings and infection among very low birth weight infants. Pediatrics, 102, E38.

Ito, J., Saijo, H., Araki, A., Tanaka, H., Tasaki, T., Cho, K., et al. (1996). Assessment of visuoperceptual disturbance in children with spastic diplegia using measurements of the lateral ventricles on cerebral MRI. Developmental Medicine and Child Neurology, 38, 496-502.

Jakobson, L. S., Frisk, V., \& Downie, A. L. S. (2006). Motion-defined form processing in extremely premature children. Neuropsychologia, 44, 1777-1786. 
Jensen, C. L., Voigt, R. G., Llorente, A. M., Peters, S. U., Prager, T. C., Zou, Y. L., et al. (2010). Effects of Early Maternal Docosahexaenoic Acid Intake on Neuropsychological Status and Visual Acuity at Five Years of Age of Breast-Fed Term Infants. The Journal of Pediatrics, 157, 900-905. doi: DOI: 10.1016/j.jpeds.2010.06.006

Jorgensen, M. H., Hernell, O., Lund, P., Holmer, G., \& Michaelsen, K. F. (1996). Visual acuity and erythrocyte docosahexaenoic acid status in breast-fed and formula-fed term infants during the first four months of life. Lipids, 31, 99-105.

Koeda, T., \& Takeshita, K. (1992). Visuo-perceptual impairment and cerebral lesions in spastic diplegia with preterm birth. Brain Dev, 14, 239-244.

Kubova, Z., Kuba, M., Spekreijse, H., \& Blakemore, C. (1995). Contrast dependence of motion-onset and pattern-reversal evoked potentials. Vision Research, 35, 197-205.

Kushner, B. J. (1982). Strabismus and amblyopia associated with regressed retinopathy of prematurity. Archives of Ophthalmology, 100, 256-261.

Lamptey, M. S., \& Walker, B. L. (1978). Learning behavior and brain lipid composition in rats subjected to essential fatty acid deficiency during gestation, lactation and growth. Journal of Nutrition, 108, 358-367.

Le, H. D., Meisel, J. A., de Meijer, V. E., Gura, K. M., \& Puder, M. (2009). The essentiality of arachidonic acid and docosahexaenoic acid. Prostaglandins Leukotrienes and Essential Fatty Acids, 81, 165-170.

Lee, J. S., \& Polin, R. A. (2003). Treatment and prevention of necrotizing enterocolitis. Semin Neonatol, 8, 449-459.

Levi, D. M., \& Klein, S. (1982). Hyperacuity and amblyopia. Nature, 298, 268-270.

Levi, D. M., \& Klein, S. A. (1992). The role of local contrast in the visual deficits of humans with naturally occurring amblyopia. Neuroscience Letters, 136, 63-66.

Litman, B. J., \& Mitchell, D. C. (1996). A role for phospholipid polyunsaturation in modulating membrane protein function. Lipids, 31 Suppl, S193-197.

Livingstone, M., \& Hubel, D. (1988). Segregation of form, color, movement, and depth: anatomy, physiology, and perception. Science, 6, 740-749.

Lucas, A., Morley, R., Cole, T. J., Lister, G., \& Leeson-Payne, C. (1992). Breast milk and subsequent intelligence quotient in children born preterm. Lancet, 339, 261-264.

Lumley, J. (2003). Defining the problem: the epidemiology of preterm birth. Bjog-an International Journal of Obstetrics and Gynaecology, 110 Suppl 20, 3-7. 
MacKay, T. L., Jakobson, L. S., Ellemberg, D., Lewis, T. L., Maurer, D., \& Casiro, O. (2005). Deficits in the processing of local and global motion in very low birthweight children. Neuropsychologia, 43, 1738-1748.

Madan, A., Jan, J. E., \& Good, W. V. (2005). Visual development in preterm infants. Developmental Medicine and Child Neurology, 47, 276-280.

Makrides, M., Gibson, R. A., \& McPhee, J. (2009). Neurodevelopmental outcomes of preterm infants fed high-dose Docosahexanoic acid: A randomized controlled trial. JAMA, 301, 175-182.

Makrides, M., Neumann, M., Simmer, K., Pater, J., \& Gibson, R. (1995). Are long-chain polyunsaturated fatty acids essential nutrients in infancy? Lancet, 345, 1463-1468.

Makrides, M., Neumann, M. A., Byard, R. W., Simmer, K., \& Gibson, R. A. (1994). Fatty acid composition of brain, retina, and erythrocytes in breast- and formula-fed infants. American Journal of Clinical Nutrition, 60, 189-194.

Manley, B. J., Makrides, M., Collins, C. T., McPhee, A. J., Gibson, R. A., Ryan, P., et al. (2011). Highdose docosahexaenoic acid supplementation of preterm infants: respiratory and allergy outcomes. Pediatrics, 128, e71-77.

Manny, R. E., \& Klein, S. A. (1984). The development of vernier acuity in infants. Current Eye Research, 3, 453-462. doi: 10.3109/02713688408997233

Maples, W. C. (2003). Visual factors that significantly impact academic performance. Optometry, 74, 35-49.

Martinez, M. (1992). Tissue levels of polyunsaturated fatty acids during early human development. Journal of Pediatrics, 120, S129-138.

Maunsell, J. H., Nealey, T. A., \& DePriest, D. D. (1990). Magnocellular and parvocellular contributions to responses in the middle temporal visual area (MT) of the macaque monkey. Journal of Neuroscience, 10, 3323-3334.

McGrath, M., \& Sullivan, M. (2002). Birth weight, neonatal morbidities, and school age outcomes in full-term and preterm infants. Issues Compr Pediatr Nurs, 25, 231-254.

McKee, S. P., Levi, D. M., \& Movshon, J. A. (2003). The pattern of visual deficits in amblyopia. J Vis, 3, 380-405.

Mendes, M., Silva, F., Simoes, L., Jorge, M., Saraiva, J., \& Castelo-Branco, M. (2005). Visual magnocellular and structure from motion perceptual deficits in a neurodevelopmental model of dorsal stream function. Brain Res Cogn Brain Res, 25, 788-798.

Merigan, W. H., \& Maunsell, J. H. (1990). Macaque vision after magnocellular lateral geniculate lesions. Visual Neuroscience, 5, 347-352. 
Merigan, W. H., \& Maunsell, J. H. (1993). How parallel are the primate visual pathways? Annual Review of Neuroscience, 16, 369-402.

Mirabella, G., Kjaer, P. K., Norcia, A. M., Good, W. V., \& Madan, A. (2006). Visual development in very low birth weight infants. Pediatric Research, 60, 435-439.

Mitchell, A. S., Baxter, M. G., \& Gaffan, D. (2007). Dissociable performance on scene learning and strategy implementation after lesions to magnocellular mediodorsal thalamic nucleus. Journal of Neuroscience, 27, 11888-11895.

Mitchell, J. P. (2006). Mentalizing and Marr: an information processing approach to the study of social cognition. Brain Research, 1079, 66-75.

Morand, S., Thut, G., de Peralta, R. G., Clarke, S., Khateb, A., Landis, T., et al. (2000).

Electrophysiological evidence for fast visual processing through the human koniocellular pathway when stimuli move. Cereb Cortex, 10, 817-825.

Narayanan, K., \& Wadhwa, S. (1998). Photoreceptor morphogenesis in the human retina: a scanning electron microscopic study. Anatomical Record, 252, 133-139.

Navon, D. (1981). The forest revisited: More on global precedence. Psychological Research, 43, 1-32.

Neuringer, M., Anderson, G. J., \& Connor, W. E. (1988). The essentiality of n-3 fatty acids for the development and function of the retina and brain. Annual Review of Nutrition, 8, 517-541.

Neuringer, M., Connor, W. E., Lin, D. S., Barstad, L., \& Luck, S. (1986). Biochemical and functional effects of prenatal and postnatal omega 3 fatty acid deficiency on retina and brain in rhesus monkeys. Proceedings of the National Academy of Sciences of the United States of America, $83,4021-4025$.

Nishida, Y., Hayashi, O., Iwami, T., Kimura, M., Kani, K., Ito, R., et al. (2001). Stereopsis-processing regions in the human parieto-occipital cortex. Neuroreport, 12, 2259-2263.

Nissenkorn, I., Yassur, Y., Mashkowski, D., Sherf, I., \& Ben-Sira, I. (1983). Myopia in premature babies with and without retinopathy of prematurity. British Journal of Ophthalmology, 67, 170-173.

Niu, S. L., Mitchell, D. C., \& Litman, B. J. (2001). Optimization of receptor-G protein coupling by bilayer lipid composition II: formation of metarhodopsin II-transducin complex. Journal of Biological Chemistry, 276, 42807-42811.

Norcia, A. M., Tyler, C. W., \& Hamer, R. D. (1990). Development of contrast sensitivity in the human infant. Vision Research, 30, 1475-1486.

O'Connor, A. R., \& Fielder, A. R. (2007). Visual outcomes and perinatal adversity. Semin Fetal Neonatal Med, 12, 408-414. 
O'Connor, A. R., Stephenson, T., Johnson, A., Tobin, M. J., Moseley, M. J., Ratib, S., et al. (2002). Long-term ophthalmic outcome of low birth weight children with and without retinopathy of prematurity. Pediatrics, 109, 12-18.

O'Connor, A. R., Stephenson, T., Johnson, A., Tobin, M. J., Ratib, S., Moseley, M., et al. (2004). Visual function in low birthweight children. Br J Ophthalmol, 88, 1149-1153.

O'Connor, D. L., Hall, R., Adamkin, D., Auestad, N., Castillo, M., Connor, W. E., et al. (2001). Growth and development in preterm infants fed long-chain polyunsaturated fatty acids: a prospective, randomized controlled trial. Pediatrics, 108, 359-371.

Olsen, P., Vainionpaa, L., Paakko, E., Korkman, M., Pyhtinen, J., \& Jarvelin, M. R. (1998). Psychological findings in preterm children related to neurologic status and magnetic resonance imaging. Pediatrics, 102, 329-336.

Pavlova, M., Sokolov, A. N., Birbaumer, N., \& Krageloh-Mann, I. (2006). Biological motion processing in adolescents with early periventricular brain damage. Neuropsychologia, 44, 586-593.

Pavlova, M., Sokolov, A. N., \& Krageloh-Mann, I. (2007). Visual navigation in adolescents with early periventricular lesions: knowing where, but not getting there. Cerebral Cortex, 17, 363-369.

Pelphrey, K. A., \& Carter, E. J. (2008). Brain mechanisms for social perception: lessons from autism and typical development. Annals of the New York Academy of Sciences, 1145, 283-299.

Ploner, C. J., Gaymard, B. M., Ehrle, N., Rivaud-Pechoux, S., Baulac, M., Brandt, S. A., et al. (1999). Spatial memory deficits in patients with lesions affecting the medial temporal neocortex. Ann Neurol, 45, 312-319.

Powls, A., Botting, N., Cooke, R. W., Stephenson, G., \& Marlow, N. (1997). Visual impairment in very low birthweight children. Arch Dis Child Fetal Neonatal Ed, 76, 82-87.

Provis, J. M., van Driel, D., Billson, F. A., \& Russell, P. (1985). Development of the human retina: patterns of cell distribution and redistribution in the ganglion cell layer. Journal of Comparative Neurology, 233, 429-451.

Quinn, G. E., Dobson, V., Kivlin, J., Kaufman, L. M., Repka, M. X., Reynolds, J. D., et al. (1998). Prevalence of myopia between 3 months and $51 / 2$ years in preterm infants with and without retinopathy of prematurity. Cryotherapy for Retinopathy of Prematurity Cooperative Group. Ophthalmology, 105, 1292-1300.

Ricci, D., Romeo, D. M., Gallini, F., Groppo, M., Cesarini, L., Pisoni, S., et al. (2011). Early visual assessment in preterm infants with and without brain lesions: correlation with visual and neurodevelopmental outcome at 12 months. Early Human Development, 87, 177-182. doi: 10.1016/j.earlhumdev.2010.12.003 
Richardson, A. J., Calvin, C. M., Clisby, C., Schoenheimer, D. R., Montgomery, P., Hall, J. A., et al. (2000). Fatty acid deficiency signs predict the severity of reading and related difficulties in dyslexic children. Prostaglandins Leukotrienes and Essential Fatty Acids, 63, 69-74.

Rotstein, N. P., Aveldano, M. I., Barrantes, F. J., \& Politi, L. E. (1996). Docosahexaenoic acid is required for the survival of rat retinal photoreceptors in vitro. Journal of Neurochemistry, 66, 1851-1859.

Sabel, K.-G., Lundqvist-Persson, C., Bona, E., Petzold, M., \& Strandvik, B. (2009). Fatty acid patterns early after premature birth, simultaneously analysed in mothers' food, breast milk and serum phospholipids of mothers and infants. Lipids Health Dis, 8, 20.

SanGiovanni, J. P., Parra-Cabrera, S., Colditz, G. A., Berkey, C. S., \& Dwyer, J. T. (2000). Meta-analysis of dietary essential fatty acids and long-chain polyunsaturated fatty acids as they relate to visual resolution acuity in healthy preterm infants. Pediatrics, 105, 1292-1298.

Schechter, I., Butler, P. D., Jalbrzikowski, M., Pasternak, R., Saperstein, A. M., \& Javitt, D. C. (2006). A new dimension of sensory dysfunction: stereopsis deficits in schizophrenia. Biological Psychiatry, 60, 1282-1284.

Schulzke, S. M., Patole, S. K., \& Simmer, K. (2011). Longchain polyunsaturated fatty acid supplementation in preterm infants. Cochrane Database Syst Rev, 2, CD000375.

Shimazawa, M., Nakajima, Y., Mashima, Y., \& Hara, H. (2009). Docosahexaenoic acid (DHA) has neuroprotective effects against oxidative stress in retinal ganglion cells. Brain Research, 1251, 269-275. doi: 10.1016/j.brainres.2008.11.031

Shimojo, S., Birch, E. E., Gwiazda, J., \& Held, R. (1984). Development of vernier acuity in infants. Vision Research, 24, 721-728. doi: 10.1016/0042-6989(84)90213-x

Simmer, K. (2000). Longchain polyunsaturated fatty acid supplementation in preterm infants. Cochrane Database Syst Rev, CD000375.

Sisk, P. M., Lovelady, C. A., Dillard, R. G., Gruber, K. J., \& O'Shea, T. M. (2007). Early human milk feeding is associated with a lower risk of necrotizing enterocolitis in very low birth weight infants. Journal of Perinatology, 27, 428-433.

Skoczenski, A. M., \& Norcia, A. M. (1999). Development of VEP Vernier acuity and grating acuity in human infants. Investigative Ophthalmology and Visual Science, 40, 2411-2417.

Smithers, L. G., Gibson, R. A., McPhee, A., \& Makrides, M. (2008). Higher dose of docosahexaenoic acid in the neonatal period improves visual acuity of preterm infants: results of a randomized controlled trial. American Journal of Clinical Nutrition, 88, 1049-1056.

Smuts, C. M., Borod, E., Peeples, J. M., \& Carlson, S. E. (2003). High-DHA eggs: feasibility as a means to enhance circulating DHA in mother and infant. Lipids, 38, 407-414. 
Stein, J. (2001). The magnocellular theory of developmental dyslexia. Dyslexia, 7, 12-36.

Stephenson, T., Wright, S., O'Connor, A. R., Fielder, A. R., Johnson, A., Ratib, S., et al. (2007). Children born weighing less than $1701 \mathrm{~g}$ : visual and cognitive outcomes at 11-14 years. Archives of Disease in Childhood. Fetal and Neonatal Edition, 92, F265-270.

Tanaka, D., Jr. (1976). Thalamic projections of the dorsomedial prefrontal cortex in the rhesus monkey (Macaca mulatta). Brain Research, 110, 21-38.

Taylor, K. E., Higgins, C. J., Calvin, C. M., Hall, J. A., Easton, T., McDaid, A. M., et al. (2000). Dyslexia in adults is associated with clinical signs of fatty acid deficiency. Prostaglandins Leukotrienes and Essential Fatty Acids, 63, 75-78.

Taylor, N. M., Jakobson, L. S., Maurer, D., \& Lewis, T. L. (2009). Differential vulnerability of global motion, global form, and biological motion processing in full-term and preterm children. Neuropsychologia, 47, 2766-2778.

Uauy, R. D., Birch, D. G., Birch, E. E., Tyson, J. E., \& Hoffman, D. R. (1990). Effect of dietary omega-3 fatty acids on retinal function of very-low-birth-weight neonates. Pediatric Research, 28, 485-492.

Uauy, R. D., Hoffman, D. R., Mena, P., Llanos, A., \& Birch, E. E. (2003). Term infant studies of DHA and ARA supplementation on neurodevelopment: results of randomized controlled trials. Journal of Pediatrics, 143, S17-25.

van den Hout, B. M., Stiers, P., Haers, M., van der Schouw, Y. T., Eken, P., Vandenbussche, E., et al. (2000). Relation between visual perceptual impairment and neonatal ultrasound diagnosis of haemorrhagic-ischaemic brain lesions in 5-year-old children. Developmental Medicine and Child Neurology, 42, 376-386.

van Houwelingen, A. C., Sorensen, J. D., Hornstra, G., Simonis, M. M., Boris, J., Olsen, S. F., et al. (1995). Essential fatty acid status in neonates after fish-oil supplementation during late pregnancy. British Journal of Nutrition, 74, 723-731.

van Meeteren, M. E., Baron, W., Beermann, C., Dijkstra, C. D., \& van Tol, E. A. F. (2006).

Polyunsaturated fatty acid supplementation stimulates differentiation of oligodendroglia cells. Developmental Neuroscience, 28, 196-208. doi: 10.1159/000091917

Velzing-Aarts, F. V., van der Klis, F. R., van der Dijs, F. P., van Beusekom, C. M., Landman, H., Capello, J. J., et al. (2001). Effect of three low-dose fish oil supplements, administered during pregnancy, on neonatal long-chain polyunsaturated fatty acid status at birth. Prostaglandins Leukotrienes and Essential Fatty Acids, 65, 51-57.

Vohr, B. R., Poindexter, B. B., Dusick, A. M., McKinley, L. T., Wright, L. L., Langer, J. C., et al. (2006). Beneficial effects of breast milk in the neonatal intensive care unit on the developmental 
outcome of extremely low birth weight infants at 18 months of age. Pediatrics, 118, e115123.

Volpe, J. J. (2009). The encephalopathy of prematurity--brain injury and impaired brain development inextricably intertwined. Seminars in Pediatric Neurology, 16, 167-178.

Wasserstein, J., Barr, W. B., Zappulla, R., \& Rock, D. (2004). Facial closure: interrelationship with facial discrimination, other closure tests, and subjective contour illusions. Neuropsychologia, 42, 158-163.

Wen, S. W., Smith, G., Yang, Q., \& Walker, M. (2004). Epidemiology of preterm birth and neonatal outcome. Semin Fetal Neonatal Med, 9, 429-435.

Wheeler, T. G., Benolken, R. M., \& Anderson, R. E. (1975). Visual membranes: specificity of fatty acid precursors for the electrical response to illumination. Science, 188, 1312-1314.

WHO. (1970). The prevention of perinatal mortality and morbidity. WHO Technical Report Series. Geneva Switzerland.

Wiesel, T. N. (1982). Postnatal development of the visual cortex and the influence of environment. Nature, 299, 583-591.

Williams, C., Birch, E. E., Emmett, P. M., Northstone, K., Avon Longitudinal Study of, P., \& Childhood Study, T. (2001). Stereoacuity at age 3.5 y in children born full-term is associated with prenatal and postnatal dietary factors: a report from a population-based cohort study. American Journal of Clinical Nutrition, 73, 316-322. 


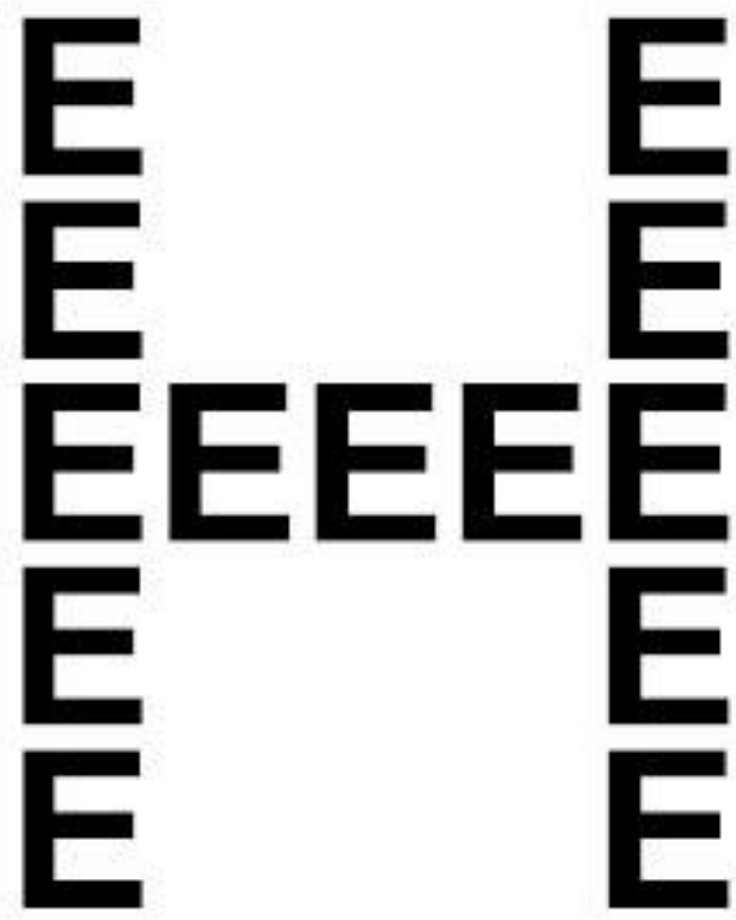

Fig 1: Example of Navon Stimulus 